\title{
A EDUCAÇÃo ANTIRRACISTA E O POEMA "TEM GENTE COM FOME", DE SOLANO TRINDADE
}

Eder Ahmad Charaf Eddine Luciano de Jesus Gonçalves ${ }^{2}$

RESUMO: O contexto da produção deste trabalho é o cenário de implantação da Lei 10.639/2003, que dispõe sobre o ensino de história e cultura afro-brasileiras. Nesse sentido, nosso artigo debate a efetivação do documento legal em face de práticas escolares cotidianas. Para isso, o trabalho está dividido em três partes. Na primeira, tratamos sobre o currículo escolar e a educação para as relações raciais; a segunda discorre sobre a literatura e a questão do negro na sociedade; e, por fim, na terceira, analisamos o poema de Solano Trindade, evidenciando tal texto como um motivador para questões antirracistas em sala de aula. Como resultado das discussões, apontamos a importância do trabalho com a literatura e autores não-canônicos em face das demandas legitimadas por legislação específica.

ABSTRACT: The context of the production of this work is the deployment scenario of Law 10,639 / 2003, which provides for the teaching of history and african-Brazilian culture. In this sense, the article debates the effectiveness of the legal document in the face of everyday school practices. For this, the work is divided into three parts. The first discuss the school curriculum and education to race relations; the second talks about literature and the issue of black society; and finally, in the third, we analyze the poem of Solano Trindade highlighting text such as a motivator for anti-racist issues in the classroom. As a result of the discussions, we pointed out the importance of working with literature and authors non-canonical in the face of demands legitimized by specific legislation.

1 Doutorando em Educação pela Faculdade de Educação da Universidade de São Paulo USP.

2 Doutorando em Literatura Brasileira pela Faculdade de Filosofia, Letras e Ciências Humanas da Universidade de São Paulo - USP. 
PALAVRAS-CHAVE: Ensino de Literatura; Educação para as relações étnico-raciais; Poesia na sala de aula

KEYWORDS: Literature Teaching. Education for racial ethnic relations. Poetry in the classroom.

\section{INTRODUÇÃO}

Querer-se branco, enquanto categoria social no Brasil, é estar propenso a praticar ou ser conivente com a discriminação racial do negro e, em outras palavras, proteger ou se dar privilégios decorrentes dessa prática. (CUTI, 2002)

inda estamos longe de implementar efetivamente a Lei
$10.639 / 2003$, que altera a Lei de Diretrizes e Bases da Educa-
ção Nacional - LDB, Lei $9.394 / 1996$, e que dispõe sobre o ensino de história e cultura afro-brasileiras. Tal desafio se constitui por estarmos inseridos em uma cultura que supervaloriza a branquitude e o branqueamento da população.

O ideal na nossa sociedade é ser branco, heterossexual e pertencente ao sexo masculino. Em meio a esse cenário, contudo, a aprovação da lei é um passo importante na construção de uma sociedade que valoriza e respeita a cultura negra brasileira. A sua defesa e implementação, na prática, serão garantidas pela escola e pelo professor.

O objetivo do trabalho é discorrer sobre o ensino interdisciplinar da literatura que, por sua vez, discute sobre a questão do negro na nossa sociedade. Tal literatura pode ser um caminho ao encontro da superação das dificuldades que as populações não-brancas enfrentam na contemporaneidade. Para ilustrar, empreendemos uma análise do poema Tem gente com fome, de Solano Trindade, negro, poeta, ator, folclorista e criador de alguns movimentos negros no Brasil do século XX. 
Inicialmente, teorizamos sobre o que entendemos por educação para as relações etnorraciais e, posteriormente, ampliamos a discussão sobre as possibilidades da literatura intencional, compreendida, aqui, como aquela que traz questões raciais no topo da discussão, na quebra do ciclo racista que as práticas e os currículos escolares ainda mantêm nas instituições educativas. Para isso, o trabalho está dividido em três partes. Na primeira, debatemos sobre o currículo escolar e a educação para as relações raciais. Na segunda, discorremos sobre a literatura e a questão do negro na sociedade. Por fim, analisamos o poema de Solano Trindade, evidenciando tal texto como um motivador para questões antirracistas em sala de aula.

\section{O CURRÍculo ESCOLAR E A EDUCAÇÃo PARA AS RELAÇões RACIAIS}

Segundo Gomes (2006, p. 31), o currículo não envolve um processo de transmissão de conhecimentos e conteúdos. "Ele possui caráter político e histórico e também constitui uma relação social, no sentido de que a produção de conhecimento nele envolvida se realiza através de uma relação entre pessoas". Por possuir caráter político e histórico, ele está sempre em transformação, não pode ser fixo e imutável e deve atender às necessidades sociais e romper com os preconceitos socioculturais. Contudo, pelo que parece, os currículos brasileiros sofrem uma pressão para que mudanças e transformações não ocorram:

A luta contra toda e qualquer forma de naturalização e estigmatização das diferenças tornou-se um dever da humanidade, pois as experiências humanas já vividas e as que assistimos nesse início do século XXI, têm-nos revelado que a intolerância, o racismo e a discriminação, ou seja, formas negativas de lidar com as diferenças, poderão nos levar a intensos processos de desumanização (GOMES, 2006, p. 28).

A luta contra o racismo e contra a intolerância na escola pode ajudar a fazer com que a população negra supere os obstáculos para a 
permanência na mesma. Segundo Abramowicz e Oliveira (2006, p. 41), os resultados estatísticos mostram as dificuldades que alunos negros enfrentam para permanecer na escola, "apresentando uma trajetória escolar diferenciada em relação aos brancos, sendo que as maiores taxas de evasão e repetência se encontram entre os negros".

A partir do levantamento de pesquisas com relação à educação racial, as autoras apontam que a instituição escolar deve dar visibilidade para questões referentes ao racismo, possibilitando

[...] um espaço permanente para discussão e reflexão de posturas racistas e preconceituosas visando à superação de estereótipos, estigmas e discriminação contra os negros que é tão presente no ambiente escolar e que interfere na construção de uma identidade positiva da criança negra (ABRAMOWICZ; OLIVEIRA 2006, p. 53).

Sem ações permanentes na escola, continuaremos ridicularizando, depreciando, estigmatizando e, principalmente, excluindo o outro, o diferente, e, segundo as pesquisadoras, tudo com anuência dos profissionais da educação, quando estes "silenciam ou participam dessas situações" (ABRAMOWICZ; OLIVEIRA 2006, p. 55).

A questão da formação do professor também é apontada em meio a tais problemas. As estudiosas afirmam que somos formados para trabalhar com um aluno ideal e, ao chegar na sala de aula, a realidade é outra:

Fomos formados para trabalhar com um aluno "ideal", hipotético. No entanto, não o encontramos, mas nos deparamos na maioria das vezes com alunos que não chegam "limpinhos" na escola, que não usam roupas e tênis novos, que não aprendem tudo com a maior rapidez, que são impacientes com o que ensinamos e achamos ser o essencial para a vida dele (ABRAMOWICZ; OLIVEIRA 2006, p. 58). 
O aluno não é o que está apresentado no livro didático e desperta o despreparo que a formação proporciona, uma formação que incorpora o discurso da diferença como um desvio e não como algo enriquecedor das práticas e das relações entre as crianças. Só uma educação que valoriza e respeita a pluralidade social desperta nos alunos a capacidade de enfrentamento ao racismo e uma postura mais aberta às diferenças.

Essa seria uma postura que reclama afetos, uma nova forma de se relacionar com o diferente, com o estrangeiro, ou seja, com a diversidade, com o outro que não é um "mesmo" de mim, pois é na relação com o outro que construímos nossa subjetividade, nossas diferenças, é a urgência da constituição de subjetividades outras, livres da clausura causada pelo modelo ideal[...] (ABRAMOWICZ; OLIVEIRA 2006, p. 59).

Diante da necessidade e da obrigatoriedade do ensino da Literatura no âmbito do Ensino Médio, entendemos a obra de arte, estética em suas formulações de conteúdo e forma, como instrumento de fruição e reflexão, ao mesmo tempo. No caso da área Linguagem, Códigos e suas Tecnologias, em que se encontram a Língua Portuguesa e a Literatura, esse aluno concreto será cobrado naquele que tem sido o principal instrumento de medição do conhecimento nessa fase da formação escolar, O Exame Nacional do Ensino Médio, em critérios pautados no reconhecimento da diversidade e na formulação de juízos críticos.

Para não nos alongarmos nessas justificativas, apontamos o fato de que na elaboração da Redação, por exemplo, entendida como uma parte específica desse exame, o aluno será avaliado em sua construção crítica de um problema de ordem política, social ou cultural sem atentar contra os direitos da pessoa humana. Ou seja, a capacidade de síntese e elaboração de uma tese que solucione tal problema não deve prescindir do respeito e da defesa dos direitos humanos. $O$ trabalho consciente do professor, em consonância com os dispositivos legais, 
realizado durante todo o Ensino Médio, pode evitar algumas dificuldades nesse plano. ${ }^{3}$

\section{A LITERATURA E AS QUESTÕES DO NEGRO NA SOCIEDADE}

O ensino interdisciplinar nas escolas pode romper com o preconceito e trazer uma visão mais ampla e menos estigmatizada das diferenças sociais e culturais. Uma das disciplinas que auxilia na busca desse rompimento é a Literatura, que, segundo Compagnon (2012), oferece conhecimento capaz de esclarecer os comportamentos e as motivações humanas, ensinando a melhor sentir. "A literatura é um exercício de pensamento; a leitura, uma experimentação dos possíveis" (p. 66).

A Literatura pode mudar vidas, não apenas em um sentido utópico de que ela reconstrói a realidade, mas também, ao desvelar sentidos sociais, culturais e históricos, trazendo formas de enxergar a realidade e, também, novas configurações subjetivas para combater preconceitos e discriminações.

Não estamos tratando de qualquer literatura, mas uma literatura que rompa com os estereótipos construídos sobre o negro e que combata o brancocentrismo ocidental (FONSECA, 2011). Que o negro não seja somente o falo poderoso, o selvagem, o instintivo, o de alma ruim, o perigoso, o submisso e o bestializado, como aponta Fonseca (2011), em suas análises da representação do negro nos textos literários. Notamos, contudo, que, mesmo no trabalho com tais textos, a preparação teórica do professor será exigida sobremaneira. Nesses casos, o problema do acesso a diferentes obras literárias tem que ser superado.

Segundo Fonseca (2011), existem manifestações literárias que são marcadas por um forte compromisso com a conscientização e que não desprezam o cuidado com o trabalho no nível da linguagem, não trazendo somente o sentido político do Movimento Negro.

3 A esse respeito, cf. o documento que afirma que, em seu texto, o candidato terá que "elaborar proposta de intervenção para o problema abordado, respeitando os direitos humanos"(BRASIL, 2016, p. 90). 
Deve-se destacar que, na literatura dita negra ou afro-brasileira, as imagens do negro circulam com intenções que se marcam pela autoconscientização e pela imposição de ampliar o espaço de visibilidade dos negros e de seus descendentes, independentemente da cor da pele, do tipo de cabelo ou da carnadura do corpo. A luta por maior visibilidade nos diferentes espaços com que se desenham os mapas das cidades atuais almeja reverter as associações que ligam os negros à feiúra, à sujeira, ao que está fora dos padrões determinantes de um gosto estético e construir uma semântica que esvazie os significados negativos gravados no corpo negro e nos lugares por onde ele é levado a circular (FONSECA, 2011, p. 266).

Essa atenção aos autores e textos que não foram consagrados por uma dada tradição literária pode contribuir, inclusive, para a compressão daquilo que tem sido estudado de maneira exaustiva. O cotejamento entre autores tradicionais, malditos, marginais, contemporâneos, famosos ou não, garante uma aprendizagem diversa.

\section{SOLANO TRINDADE: O POETA NEGRO E SUA POESIA NA ESCOLA}

Para exemplificar o que foi escrito acima, segue um exemplo de literatura que estamos sugerindo como motivadora para discussões antirracistas e sobre o negro em sala de aula: O poema Tem gente com fome, de Solano Trindade, escritor e criador do Teatro Experimental do Negro - TEN.

Trindade, nascido em Recife, em 24 de julho, de 1908, segundo Munanga e Gomes (2006), é o criador da poesia assumidamente negra no Brasil. "Premiado no exterior, elogiado por celebridades como Darcy Ribeiro, Sérgio Millet e outros, o negro 'e pobre' escritor recifense é muito pouco lembrado, apesar de tudo o que fez pela cultura e pelas artes no país" (p. 125).

Solano Trindade foi idealizador do $1^{\circ}$ Congresso Afro-brasileiro e, em 
1932, criou, no Recife, a Frente Negra Pernambucana, movimento que não vingou. Viveu no Rio de Janeiro e em São Paulo, teve grande fama entre a crítica nacional e realizava oficinas para operários, estudantes e desempregados. "Em 1944, durante a ditadura do Estado Novo, por conta do poema Tem gente com fome, foi preso e teve o livro Poemas de uma vida simples, apreendido" (MUNANGA; GOMES, 2006, p. 126).

Em 1950, criou, juntamente com o sociólogo Edison Carneiro, o Teatro Popular Brasileiro (TPB) e, em 1955, o grupo de dança Brasiliana que bateu recorde de apresentações no exterior. Solano Trindade foi o primeiro a encenar a peça Orfeu da Conceição, de Vinícius de Moraes, em 1956.

Todo o trabalho de Solano Trindade, quer no teatro, dança, cinema ou literatura, tinha como características marcantes o resgate da arte popular e, sobretudo, a luta em prol da independência cultural do negro no Brasil (MUNANGA; GOMES, 2006, p. 126).

Em 1964, um de seus quatro filhos, Francisco, morreu assassinado num presídio carioca durante a ditadura militar. Em 20 de fevereiro, de 1974, fora a vez do poeta, que morreu como indigente em uma clínica em Santa Tereza, no Rio de Janeiro.

Abaixo, o poema ilustra o caráter denunciativo da poesia de Solano Trindade e seu engajamento com a luta contra a opressão sofrida pelo negro na sociedade brasileira:

\section{CIVILIZAÇÃO BRANCA}

LINCHARAM um homem

entre os arranha-céus

(li num jornal)

procurei o crime do homem

o crime não estava no homem

estava na cor de sua epiderme ${ }^{4}$

4 TRINDADE, S. Civilização branca. In: . Cantares ao meu povo. São Paulo: Fulgor, 
O poema acima é marcado pelo rompimento da ideologia de que no Brasil há uma Democracia Racial e relata como o negro é tratado na sociedade. Fala da violência que sofre por estar em uma cultura de valorização do branco.

No texto, a condição criminal se confunde com a cor da pele. Essa pele será a prova para a condenação imediata. No cenário mercantil, mais um homem negro é linchado.

A partir desse momento, iremos nos ater ao poema anunciado já em nosso título. A intenção é discutir como a Literatura pode suscitar discussões frutíferas na sala, não somente nas aulas de Língua Portuguesa e Literatura, mas em diversas disciplinas como História, Artes, Geografia, entre outras. O poema selecionado Tem gente com fome é o mais famoso de Solano Trindade que, em 2008, foi lançado em livro infantil em comemoração ao centenário de nascimento do autor.

\section{TEM GENTE COM FOME}

Trem sujo da Leopoldina

correndo correndo

parece dizer

tem gente com fome

tem gente com fome

tem gente com fome

\section{Piiiiii}

Estação de Caxias

de novo a dizer

de novo a correr

tem gente com fome

tem gente com fome

1961, p. 37. Disponível em: http://www.elfikurten.com.br/2015/06/solano-trindade.html. Acesso em: 25 dez de 2015. 
tem gente com fome

Vigário Geral

Lucas

Cordovil

Brás de Pina

Penha Circular

Estação da Penha

Olaria

Ramos

Bom Sucesso

Carlos Chagas

Triagem, Mauá

trem sujo da Leopoldina

correndo correndo

parece dizer

tem gente com fome

tem gente com fome

tem gente com fome

Tantas caras tristes

querendo chegar

em algum destino

em algum lugar

Trem sujo da Leopoldina correndo correndo parece dizer

tem gente com fome tem gente com fome tem gente com fome

Só nas estações quando vai parando 
lentamente começa a dizer

se tem gente com fome

dá de comer

se tem gente com fome

dá de comer

se tem gente com fome

dá de comer

Mas o freio de ar

todo autoritário

manda o trem calar

Psiuuuuuuuuuuu ${ }^{5}$

Não se pode deixar de contextualizar que o poema foi duas vezes censurado no Brasil, uma em 1944; e, outra, em 1975, nos dois regimes ditatoriais brasileiros. Ele incomoda o processo governamental por denunciar as mazelas sociais que a população pobre e negra sofria no Brasil. Refletir que, ainda em 2016, esses problemas estão na ordem do dia, provoca tristeza e convoca ao debate para tais questões.

Na primeira vez em que o escrito foi censurado, o autor foi preso e seu livro retirado de circulação. Na segunda vez, o grupo Secos \& Molhados não conseguiu gravar o poema musicado por João Ricardo. A música só foi gravada por Ney Matogrosso em 1979, no álbum Seu Tipo.

Fernandes (2011) relata que o trabalho de Solano Trindade é a voz do negro e do pobre e

[...] carrega em seu "trem sujo da Leopoldina" toda a angústia, pobreza, falta de afeto e injustiça a qual estão submetidos os infelizes passageiros do cotidiano, abafados pelo "autoritário apito do trem" (FERNANDES, 2011, p. 18).

5 TRINDADE apud MUNANGA; GOMES, 2006, p. 126-128. 
O poema se insere em uma reivindicação para se atentar aos problemas da sociedade. Esses trabalhos estão incluídos numa:

[...] nova postura metodológica [por] contribuir para o rompimento da política de silêncio que sempre se abateu sobre aquilo que era visto como "não-canônico" e, por isso mesmo, posto à margem do que a cultura literária hegemônica consagrava e ainda consagra. (PADILHA apud FERNANDES, 2011, p. 18)

Essa postura tenta romper com o processo hegemônico da sociedade, traz o que é subversivo, o que está na contracorrente da literatura embranquecida. O poema denuncia a fome em um país no qual ainda hoje os brancos detêm mais de $74 \%$ da renda brasileira. Ou seja:

O abismo racial brasileiro existe, de fato, e são as pesquisas e estatísticas que comparam as condições de vida, emprego, escolaridade entre brancos e negros, que comprovam a existência da grande desigualdade racial em nosso país. Essa desigualdade é fruto da estrutura racista, somada à exclusão social e à desigualdade socioeconômica, que atinge toda a população brasileira e, de modo particular, os negros. (MUNANGA; GOMES, 2006, p. 172)

Em uma estrutura cultural e social branca, o negro é o que mais sofre. O poema não fala da pigmentação da pele ou da raça de quem passa fome, mas é notório que no Brasil a exclusão social é maior entre a população negra, que está, em sua maioria, à margem das condições ideais de trabalho, renda e escolaridade.

O poema se utiliza do trajeto do trem que vai da Estação Leopoldina até a Estação Mauá. Em sua travessia, percorre o subúrbio do Rio de Janeiro, algumas favelas e bairros de classe média.

Partindo do título, na língua portuguesa, o verbo "ter" apresenta uma variedade de acepções. Essa variedade atesta o seu poder de alcance linguístico no uso diário. Em sua primeira utilização no poema de Trindade, na abertura do título, chama a atenção pela construção resultante. 
O efeito obtido é a de um sujeito indeterminado. A expressão "tem gente com fome" se aproximaria de um ideal normativo se fosse construída com o verbo "haver", no sentido de existir. As duas ocorrências, por outro lado, atestam o nível de indeterminação dessa gente, tratada num coletivo agrupador de miseráveis. A escolha do poeta reforça, ainda, a aproximação com a simplicidade da língua coloquial e será repetida em forma de estribilhos (refrões) em mais quatro passagens.

O verso de abertura do poema é aquele que traz a única descrição do trem observado desde a sua partida. Estamos falando de um sujeito elíptico que é, puramente, sujo. A insígnia será repetida mais duas vezes (no vigésimo quinto e no trigésimo quinto versos), mas será, apenas, isso.

A primeira estrofe define a estação de origem, a Leopodina. A tônica do verbo no presente contínuo (correndo, correndo), alia-se ao estribilho, que será usado para criar a imagem do movimento ferroviário. A dinâmica será marcada pela aliteração, a repetição constante das consoantes nasaladas.

Em seguida, há a primeira ocorrência onomatopeica em uma estrofe de um verso isolado. O "piiiiii" confirma: o trem já partiu. Daí em diante, veremos no poema, de maneira acentuada, o trabalho com os recursos fonéticos para a manutenção desse carro em movimento.

Ao passar por Caxias, segunda estação, o objeto personificado alardeia, enquanto corre, "tem gente com fome". O refrão continua a ser martelado pelo eu lírico que observa o movimento renitente.

A próxima estrofe irá acentuar movimento e velocidade na medida em que lista, num fôlego só, onze estações ou localidades. Os versos formados pelo verbo "correr", no gerúndio, repetido uma vez, se juntam ao efeito de movimento, cada vez mais, acentuado.

A estrofe que registra as "caras", conduzidas nesse trem sujo, é aquela que nos revela o segundo adjetivo do poema. Tais caras, assim mesmo, sem revelar quaisquer identidades específicas, são tristes.

Os efeitos, a esta altura, seguem na mesma linha da indeterminação do sujeito. A falta de nominação revela a desfiliação daquele que se locomove por um objeto coberto de sujeira. 
Mais para o final da composição, é notável a inserção de outro modo verbal, o imperativo. Por meio de uma conclusão lógica e causal, o eu lírico reproduz a locomotiva. Ao iniciar a parada, a reflexão é certa: o lenitivo para a fome é a comida.

Mas a construção poética não é tão denotativa quanto a que reproduzimos acima. Ao refrão, já conhecido nessa altura, será acrescentada a partícula "se", conjunção que expressa a causalidade entre a existência da fome e a necessidade de alimentar quem se encontra nesse estado.

O ciclo dos adjetivos é encerrado com o fim da viagem. O freio do ar é "autoritário". A reivindicação será calada por mais uma onomatopeia. "Psiuuuuuuuuuuu", vocifera.

Por meio de recursos que flertam com a oralidade, evidenciando a riqueza do coloquial do meio de figuras como a onomatopeia, aliteração, personificação e metáforas, o poeta parece alçar o trajeto do trem à dignidade de um feito heroico, que pode ser tratado em um poema épico ${ }^{6}$. O resultado é um poema narrativo heroico de uma lataria que erra por um destino traçado, sôfrego e cíclico.

\section{CONSIDERAÇÕES FINAIS}

A importância de trazer literatos negros e/ou literatura que retrata o negro para a sala de aula não está somente para atender à LDB, mas numa reivindicação cultural. Mostrar a produção não-hegemônica e não-canônica é valorizar a pluralidade cultural brasileira.

O uso interdisciplinar da literatura pode ser visualizado no poema de Solano Trindade, ao qual o professor pode recorrer para explicar História, relatando as dificuldades do negro e do pobre na ditadura da Era Vargas; na Geografia pode fazer o trajeto do trem e os percursos de um Rio de Janeiro marcado pelas desigualdades; na Língua Portuguesa e Literatura, como aponta Fontes e Carvalho (2010), pode trabaIhar a fonética como um momento de ampliação cultural.

6 Cf. ALVES, H. Epopeia. In: Ceia, C. E-Dicionário de Termos Literários. Disponível em: http:// edtl.fcsh.unl.pt/business-directory/6048/epopeia/ . Acesso em 14 de abr. de 2016. 
O presente trabalho não reafirma, pura e simplesmente, que a literatura deva ser útil, mas que, o trabalho docente, ao usar a interdisciplinaridade dessa manifestação artística, unindo formas de romper com o braqueamento da sociedade e com o racismo, é de suma importância para a garantia dos direitos de populações que sempre estiveram marcadas pela injustiça social. No horizonte do professor, marcado por uma atuação política, há sempre estudantes e profissionais da educação que precisam ser emancipados.

\section{REFERÊNCIAS BIBLIOGRÁFICAS}

ABRAMOWICZ, A.; OLIVEIRA, F. A escola e a construção da identidade na diversidade. In: ABRAMOWICZ, A.; BARBOSA, L. M. A.; SILVÉRIO, V. R. (Orgs.). Educação como prática da diferença. Campinas: Armazém do Ipê (Autores Associados), 2006, p. 41-63.

ALVES, H. Epopeia. In: Ceia, C. E-Dicionário de Termos Literários. Disponível em: http://edtl.fcsh.unl.pt/business-directory/6048/epopeia/ . Acesso em 14 de abr. de 2016.

FONTES, B.; CARVALHO, J. Fonética em sala de aula: um momento de ampliação cultural. Educação Pública, Língua Portuguesa, Rio de Janeiro, 03 ago. 2010. Disponível em: <http://www.educacaopublica.rj.gov.br/ biblioteca/portugues/0029.html>. Acesso em: 26 dez. 2015.

COMPAGNON, A. Literatura para que? Belo Horizonte: UFMG, 2012.

CUTI (Luiz Silva). O leitor e o texto afro-brasileiro. In: FIGUEIREDO, M. C. L.; FONSECA, M. N. S. (Org.). Poéticas afro-brasileiras. Belo Horizonte: Editora PUC Minas, 2002, p. 19-36.

FERNANDES, B. Literatura e identidade: poesia de representação em busca de uma cidadania negada. O Cabo dos Trabalhos. Revista Electrónica dos Programas de Mestrado e Doutoramento do CES/ FEUC/ FLUC, Coimbra, $n^{\circ}$ 6, p. 1-30, 2011. Disponível em: <cabodostrabalhos.ces.uc.pt/ n6/documentos/04-BrunoFernandes.pdf >. Acesso em: 26 dez. 2015. 
FONSECA, M. N. S. Literatura negra: os sentidos e as ramificações. In: DUARTE, E. A.; FONSECA, M. N. (Org.). Literatura e afrodescendência no Brasil: antologia crítica. Belo Horizonte: Editora UFMG, 2011, p. 245-277. GOMES, N. L. Diversidade cultural, currículo e questão racial: desafios para a prática pedagógica. In: ABRAMOWICZ, A.; BARBOSA, L. M. A.; SILVÉRIO, V. R. (Orgs.). Educação como prática da diferença. Campinas: Armazém do Ipê (Autores Associados), 2006, p. 21-40.

MUNANGA, K.; GOMES, N. L. O negro no Brasil de hoje. São Paulo: Global, 2006.

TRINDADE, S. Civilização branca. In: MUNANGA, K. Cantares ao meu povo. São Paulo: Fulgor, 1961, p. 37. Disponível em: http://www.elfikurten.com.br/2015/06/solano-trindade.html. Acesso em: 25 dez de 2015. 